\title{
Role of Hospitalists in an Offsite Alternate Care Center (ACC) for Pandemic Flu
}

\author{
Christopher S. Kim, MD, MBA ${ }^{1,2}$ \\ James C. Pile, $\mathrm{mD}^{3,4}$ \\ Marie M. Lozon, $\mathrm{MD}^{2,5}$ \\ William M. Wilkerson, ${ }^{5}{ }^{5}$ \\ Carrie M. Wright, вA, мs ${ }^{6}$ \\ Sandro Cinti, MD ${ }^{1}$
}

\author{
${ }^{1}$ Department of Internal Medicine, University of Michigan, Ann Arbor, Michigan. \\ ${ }^{2}$ Department of Pediatrics and Communicable Diseases, University of Michigan, Ann Arbor, Michigan. \\ ${ }^{3}$ Division of Hospital Medicine, Metro Health Medical Center, Cleveland, Ohio. \\ ${ }^{4}$ Division of Infectious Diseases, Metro Health Medical Center, Cleveland, Ohio. \\ ${ }^{5}$ Department of Emergency Medicine, University of Michigan, Ann Arbor, Michigan. \\ ${ }^{6}$ University of Michigan Hospitals and Health Centers, Ann Arbor, Michigan.
}

Disclosure: Nothing to report.

Recent concerns about an influenza pandemic have highlighted the need to plan for offsite Alternate Care Centers (ACCs). The likelihood of a successful response to patient surges will depend on the local health systems' ability to prepare well in advance of an influenza pandemic. Our health system has worked closely with our state's medical biodefense network to plan the establishment of an ACC for an influenza pandemic. As hospitalists have expanded their roles in their local health systems, they are poised to play a major role in planning for the next influenza pandemic. Hospitalists should work with their health system's administration in developing an ACC plan. Journal of Hospital Medicine 2009;4:546-549. @ 2009 Society of Hospital Medicine.

\section{KEYWORDS: alternate care center, hospitalist, pandemic influenza, surge capacity.}

Major natural disasters, such as Hurricane Rita and Hurricane Katrina in 2005, have reinforced the reality that health care workers may be asked to treat patients outside the traditional hospital setting. ${ }^{1}$ The emergence of H5N1 avian influenza in Southeast Asia has also raised concerns about a potential worldwide pandemic influenza. ${ }^{2}$ Since 2003, the number of avian influenza cases in humans has totaled 387, with 245 deaths. ${ }^{3}$ While H5N1 influenza has thus far been largely confined to avian populations, the virulence of this strain has raised concern regarding the possible emergence of enhanced human transmission. ${ }^{4}$ While impossible to accurately forecast the devastation of the next pandemic on the health system, anything similar to the pandemics of the past century will require a large coordinated response by the health system. The most severe pandemic in the past century occurred in 1918 to 1919. The estimated deaths attributed to this worldwide ranges from 20 to 100 million persons, ${ }^{5-7}$ with $>500,000$ of these deaths in the United States. ${ }^{6,7}$ In comparison, the annual rate of deaths related to influenza in the United States ranges from 30,000 to $50,000 .^{2,5}$ It has been estimated that the next pandemic influenza could cause 75 to 100 million people to become ill, and lead to as many as 1.9 million deaths in the United States. ${ }^{8}$ In response, the Department of Health and Human Services (HHS) has stressed the importance of advanced planning, ${ }^{9}$ and the most recent Homeland Security Presidential Directive (HSPD-21) directs health care organizations and the federal government to develop preparedness plans to provide surge capacity care in times of a catastrophic health event. ${ }^{10}$ A previous report by one of the authors emphasized the need for hospitalists to play a major role in institutional planning for a pandemic influenza. ${ }^{11}$

\section{The Alternate Care Center}

The concept of offsite care in an influenza pandemic has previously been described, and we will refer to these as Alternate Care Centers (ACCs). Although the literature describes different models of care at an ACC (Table 1), ${ }^{12}$ we believe an ACC should be activated as an extension of the supporting hospital, once the hospital becomes over capacity despite measures to grow its inpatient service volume.

Our health system is a large academic medical center, and we have been working with our state to develop a plan to establish and operate an ACC for the next pandemic influenza. Our plans call for an ACC to be activated as an overflow hospital once our hospitals are beyond $120 \%$ capacity. We have gone through several functional and tabletop exercises to help identify critical issues that are likely to arise during a real pandemic. Subsequent to these exercises, we have convened an ACC Planning Work Group, reviewed the available literature on surge hospitals, and have focused our recent efforts on several key areas. ${ }^{13}$ First, it will be important to clearly outline the general services that will be available at this offsite location (Table 2), and this information should be disseminated to the local medical community and the general public. An informed public, with a clear understanding that the ACC is an extension of 


\section{TABLE 1. Models of Care at an Alternate Care Center}

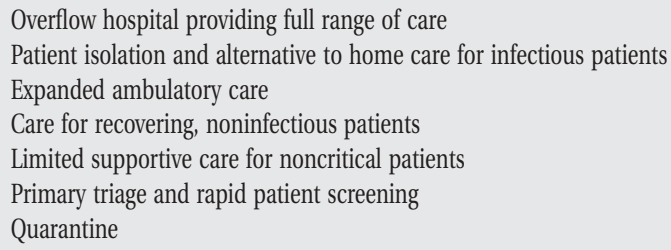

\section{TABLE 2. Examples of Medical Services at an Alternate Care Center}

IVF administration

Parenteral medication administration (eg, antibiotics, steroids, narcotic analgesics, antiemetics)

Oxygen support

Palliative care services

NOTE: Physicians, in conjunction with nurses could determine the need for, and provide these services.

Abbreviation: IVF, intravenous fluids.

the hospital with hospitalists in charge of medical care, is more likely to accept getting healthcare in this setting.

Second, hospitals and the ACC-as an extension to the main hospital-will be asked to provide care to patients referred from several external facilities. Thus, the relationship between the ACC and the main hospital is critical. In a situation where local and even national health care assets will be overwhelmed, having a traditional hospital take full ownership of the ACC and facilitate the transport of patients in and out of the center will be vital to the maintenance of operations. Figure 1 illustrates an example of how patients may be transitioned from 1 site of care to another.

Third, the logistics of establishing an ACC should include details regarding: (1) securing a location that is able to accommodate the needs of the ACC; (2) predetermining the scope of care that can be provided; (3) procuring the necessary equipment and supplies; (4) planning for an adequate number of workforce and staff members; and (5) ensuring a reliable communication plan within the local health system and with state and federal public health officials. ${ }^{14}$ Staffing shortages and communication barriers are worthy of further emphasis. Given conservative estimates that up to $35 \%$ of staff may become ill, refuse to work, or remain home to care for ill family members, ${ }^{15}$ it is essential that hospitals and regional emergency planners develop a staffing model for the ACC, well in advance of a pandemic. These may include scenarios in which the recommended provider-topatient ratio can not be met. Among the essential lessons learned from the severe acute respiratory syndrome (SARS) outbreak in Toronto (Ontario, Canada) was the importance of developing redundant and reliable communication plans among the healthcare providers. ${ }^{16,17}$

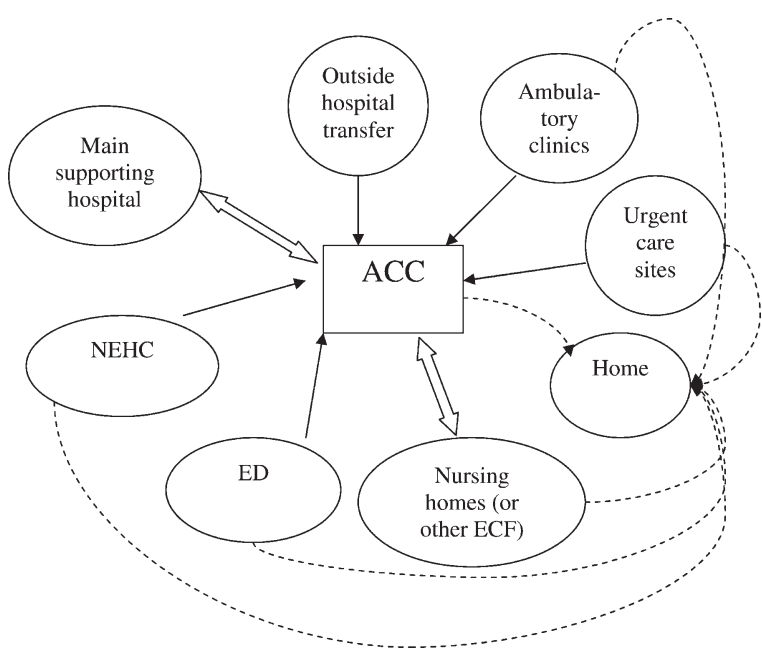

FIGURE 1. Flow of patients to and from the ACC. Although in a pandemic flu, patients may need to be transferred from many of these settings to another site, the diagram depicts the multiple ways patients may be referred to an ACC and back to home. Abbreviations: ACC, Alternate Care Center; ECF, Extended Care Facility; ED, Emergency Department; NEHC, Neighborhood Emergency Help Center.

Last, healthcare workers' concerns about occupational health and safety must be addressed, and strict measures to protect providers in the ACC need to be implemented. ${ }^{16}$ This includes providing all exposed staff with adequate personal protective equipment (eg, N-95 masks), ensuring that all staff are vaccinated against the influenza virus, and implementing strict infection control (eg, hand washing) practices.

For more information, we refer the reader to references that contain further details on our ACC exercises ${ }^{13}$ and documents that outline concepts of operations in an ACC, developed by the Joint Commission and a multiagency working group. ${ }^{1,14}$

\section{The Hospitalist Physician and the ACC}

During an influenza pandemic, physicians from all specialties will be vital to the success of the health systems' response. General internists, ${ }^{18}$ family practitioners, and pediatricians will be overextended in the ambulatory setting to provide intravenous (IV) fluids, antibiotics, and vaccines. Emergency physicians will be called upon to provide care for a burgeoning number of patient arrivals to the Emergency Department (ED), whose acuity is higher than in nonpandemic times. These physicians' clinical expertise at their sites of practice may be severely tested. Hospitalists, given their inpatient focus will be ideally suited to provide medical care to patients admitted to the ACC.

Previous physician leadership at surge hospitals has come from multiple specialties. Case studies describing the heroic physician leadership after Hurricane Katrina and Hurricane Rita represented pediatricians, family physicians, 
emergency department physicians, and internists. ${ }^{1}$ In an influenza pandemic, patients in the ACC will require medical care that would, under nonsurge situations, warrant inpatient care. Hospitalists are well poised to lead the response in the ACC for pandemic flu. Hospitalists have expanded their presence into many clinical and administrative responsibilities in their local health systems, ${ }^{19}$ and the specialty of hospital medicine has evolved to incorporate many of the skills and expertise that would be required of physician leaders who manage an ACC during an influenza pandemic.

While the actual morbidity and mortality associated with the next pandemic are uncertain, it is likely that the number of patients who seek out medical care will exceed current capacity. With constrained space and resources, patients will require appropriate and safe transition to and from the hospital and the ACC. Hospitalists have become leaders in developing and promoting quality transition of care out of acute care settings. ${ }^{20,21}$ Their expertise in optimizing this vulnerable time period in patients' healthcare experience should help hospitalists make efficient and appropriate transition care decisions even during busy times and in an alternate care location. Many hospitalists have also developed local and national expertise in quality improvement (QI) and patient safety (PS) initiatives in acute care settings. ${ }^{22}$ Hospitalists can lead the efforts to apply QI and PS practices in the ACC. These interventions should focus on the potential to be effective in improving patient care, but also consider issues such as ease of implementation, cost, and potential for harm. ${ }^{23}$

An influenza pandemic will require all levels of the healthcare system to work together to develop a coordinated approach to patient care. Previously, Kisuule et al. ${ }^{24}$ described how hospitalists can expand their role to include public health. The hospitalists' leadership in the ACC fits well with their descriptions, and hospitalists should work with local, state, and national public health officials in pandemic flu planning. Their scope of practice and clinical expertise will call on them to play key roles in recognition of the development of a pandemic; help lead the response efforts; provide education to staff, patients, and family members; develop clinical care guidelines and pathways for patients; utilize best practices in the use of antimicrobial therapy; and provide appropriate palliative care. Depending on the severity of the influenza pandemic, mortality could be considerable. Many hospitalists have expertise in palliative care at their hospitals, ${ }^{25-27}$ and this skill set will be invaluable in providing compassionate end-of-life care to patients in the ACC.

In a pandemic, the most vulnerable patient populations will likely be disproportionately affected, including the elderly, children, and the immune-compromised. Hospitalists who care regularly for these diverse groups of patients through the spectrum of illness and recovery will be able to address the variety of clinical and nonclinical issues that arise. If the ACC will provide care for children, hospitalists with training in pediatrics, medicine-pediatrics, or family medicine should be available.

\section{Additional Considerations}

While many unanswered questions remain about how to best utilize the ACC, hospitalists are ideally suited to help lead planning efforts for an ACC for pandemic flu. Other issues that may require additional considerations include: (1) whether to strictly care for patients with influenza symptoms and influenza-related illnesses or to provide care for all patients at the ACC; (2) what to do when patients refuse transfer to and from the ACC; (3) determining the optimal staffing model for patient care providers and to provide care for a wide range of age groups; (4) how the ACC will be funded; (5) how and where to store stockpiles; (6) developing redundant and coordinated communication plans; and (7) planning for reliable access to information and technology from the ACC.

\section{Conclusions}

We have introduced the concept of the ACC for the hospitalist community, and emphasized the benefits of engaging hospitalists to lead the ACC initiative at their own health organizations during pandemic flu. As hospitalists currently serve in many of these roles and possess the skills to provide care and lead these initiatives, we encourage hospitalists to contact their hospital administrators to volunteer to assist with preparation efforts.

\section{Address for correspondence and reprint requests:}

Christopher S. Kim, MD, MBA, Assistant Professor, Internal Medicine, Assistant Professor, Pediatrics and Communicable Diseases, University of Michigan Medical School, Division of General Medicine, Department of Internal Medicine, 3119

Taubman Center, Box 5376, 1500 E. Medical Center Drive, Ann Arbor, MI 48109-5376; Telephone: 734-647-2892; Fax: 734-6158401; E-mail: seoungk@umich.eduＲeceived 18 July 2008; revision received 16 December 2008; accepted 27 January 2009.

\section{References}

1. Joint Commission on Accreditation of Healthcare Organizations. Surge Hospitals: Providing Safe Care in Emergencies; 2006. Available at: http:// www.jointcommission.org/NR/rdonlyres/802E9DA4-AE80-4584-A205-48989C5BD684/0/surge_hospital.pdf. Accessed May 2009.

2. Cinti S. Pandemic influenza: are we ready? Disaster Manag Response. 2005;3(3):61-67.

3. Cumulative Number of Confirmed Human Cases of Avian Influenza A/ (H5N1) Reported to WHO. 2008. Available at: http://www.who.int/csr/ disease/avian_influenza/country/cases_table_2008_09_10/en/index.html. Accessed May 2009.

4. Gambotto A, Barratt-Boyes SM, de Jong MD, et al. Human infection with highly pathogenic H5N1 influenza virus. Lancet. 2008;371(9622): 1464-1475.

5. Osterholm MT. Preparing for the next pandemic. N Engl J Med. 2005; 352(18):1839-1842.

6. Strikas RA, Wallace GS, Myers MG. Influenza pandemic preparedness action plan for the United States: 2002 update. Clin Infect Dis. 2002;35(5): 590-596.

7. Markel H, Lipman HB, Navarro JA, et al. Nonpharmaceutical interventions implemented by US cities during the 1918-1919 influenza pandemic. JAMA. 2007;298(6):644-654. 
8. The Health Care Response to Pandemic Influenza: Position Paper. Philadelphia, PA: American College of Physicians; 2006.

9. U.S. Department of Health and Human Services (HHS). HHS Pandemic Influenza Plan. November 2005. Available at: http://www.hhs.gov/pandemicflu/plan. Accessed May 2009.

10. Homeland Security Presidential Directive/HSPD-21. 2007. Available at: http://www.whitehouse.gov/news/releases/2007/10/20071018-10.html. Accessed May 2009.

11. Pile JC, Gordon SM. Pandemic influenza and the hospitalist: apocalypse when? J Hosp Med. 2006;1(2):118-123.

12. Lam C, Waldhorn R, Toner E, Inglesby TV, O'Toole T. The prospect of using alternative medical care facilities in an influenza pandemic. Biosecur Bioterror. 2006;4(4):384-390.

13. Cinti SK, Wilkerson W, Holmes JG, et al. Pandemic influenza and acute care centers (ACCs): taking care of sick patients in a non-hospital setting. Biosecur Bioterror. 2008;6(4):335-348.

14. Skidmore S, Wall W, Church J. Acute Care Center. Modular Emergency Medical System: Concept of Operations for the Acute Care Center (ACC). Mass Casualty Care Strategy for A Biological Terrorism Incident. May 2003. Available at: http://dms.dartmouth.edu/nnemmrs/resources/surge_ capacity_guidance/documents/acute_care_center_concept_of_operations. pdf. Accessed May 2009.

15. Illinois Department of Public Health. Influenza. 2007. Available at: http://www.idph.state.il.us/flu/pandemicfs.htm. Accessed May 2009.

16. Naylor CD, Chantler C, Griffiths S. Learning from SARS in Hong Kong and Toronto. JAMA. 2004;291(20):2483-2487.
17. Weinstein RA. Planning for epidemics-the lessons of SARS. $N$ Engl J Med. 2004;350(23):2332-2334.

18. Lee BY. The role of internists during epidemics, outbreaks, and bioterrorist attacks. J Gen Intern Med. 2007;22(1):131-136.

19. Sehgal NL, Wachter RM. The expanding role of hospitalists in the United States. Swiss Med Wkly. 2006;136(37-38):591-596.

20. Kripalani S, Jackson AT, Schnipper JL, Coleman EA. Promoting effective transitions of care at hospital discharge: a review of key issues for hospitalists. J Hosp Med. 2007;2(5):314-323.

21. Coleman EA, Williams MV. Executing high-quality care transitions: a call to do it right. J Hosp Med. 2007;2(5):287-290.

22. Wachter RM. Reflections: the hospitalist movement a decade later. $J$ Hosp Med. 2006;1(4):248-252.

23. Ranji SR, Shojania KG. Implementing patient safety interventions in your hospital: what to try and what to avoid. Med Clin North Am. 2008;92(2): 275-293, vii-viii.

24. Kisuule F, Minter-Jordan M, Zenilman J, Wright SM. Expanding the roles of hospitalist physicians to include public health. J Hosp Med. 2007;2(,2): 93-101.

25. Pantilat SZ, Rabow MW, Citko J, von Gunten CF, Auerbach AD, Ferris FD. Evaluating the California hospital initiative in palliative services. Arch Intern Med. 2006;166(2):227-230.

26. Pantilat SZ. Palliative care and hospitalists: a partnership for hope. $J$ Hosp Med. 2006;1(1):5-6.

27. Meier DE. Palliative care in hospitals. J Hosp Med. 2006;1(1): 21-28. 